\title{
Difficulties Faced by the Undergraduate Medical Students in Relation to Institution and Hostel Campus: Views of Selected Medical Colleges of Bangladesh
}

\author{
Dr. Farhana Haque ${ }^{1}$ Prof. Dr. Md. Humayun Kabir Talukder ${ }^{2}$, Dr. Kazi Khairul Alam³ , Dr. Sadia Jabeen Khan', \\ Dr. Md. Rezaul Karim
}

\begin{abstract}
This study set out to identify the institutional difficulties encountered by the undergraduate medical students of Bangladesh. This was a descriptive type of cross sectional study, conducted from July 2017 to June 2018. The population of the study consisted of undergraduate medical students and medical teachers of 8 medical colleges of Bangladesh including both government and non-government which were located in Dhaka and outside of the Dhaka. Medical colleges and medical teachers were selected purposively and students were selected by the convenience sampling technique. The questionnaire using five points Likert scale were administered on 1059 medical students and in-depth interviews were conducted with 13 medical teachers. The study revealed that most of the students faced institutional related difficulties, particularly cleanliness of campus $480(45.6 \%)$, unclean toilet $762(72 \%)$, poor quality canteen $663(63 \%)$, poor games facilities $792(75 \%)$, insufficient hostel accommodation $669(65.2 \%)$, unclean hostel $652(63.5 \%)$, insufficient recreation facilities in hostel $702(68.5 \%)$ and irregular hostel supervision by the authority 590 (57.6\%). Based on the study, it was suggested that concerned authority should consider the findings and should take some significant steps for sustainable solutions to the difficulties of the students.
\end{abstract}

Keywords: Institution, Hostel campus, difficulties, Undergraduate medical students.

\section{Introduction}

Medical students are expected to learn and master a huge amount of knowledge and skills. The personal and social sacrifice they have to make in order to maintain good academic results in a highly competitive environment, puts them under a lot of stress ${ }^{1}$. Several educationists and sociologists pointed out that various student problems severely affect their learning process. In addition, some local and overseas studies have shown that there are many common factors causing students in institutions of higher education to be distressed and performing poorly or dropping out without completion of courses ${ }^{2}$. The majority of students faced institutional related problems, particularly accommodation, food and nutrition, the medium of instructions, library facilities, financial assistance, and teacher-student relationship ${ }^{2}$.

A hostel is referred to a place where people can stay when their residence is located far from the educational institution

\footnotetext{
1. Assistant Professor (Obst. \& Gynae, CC) NICRH, Mohakhali, Dhaka.

2. Professor, Curriculum Development \& Evaluation Centre for Medical Education (CME), Mohakhali, Dhaka.

3. Assistant Professor, Teaching Methodology Centre for Medical Education (CME), Mohakhali, Dhaka.

4. Assistant Professor (Obst. \& Gynae) NICRH, Mohakhali, Dhaka. 5. Junior consultant (Cardiology) DGHS, Mohakhali, Dhaka.

Address of correspondence:

Dr. Farhana Haque

Assistant Professor (Obst. \& Gynae), NICRH, Mohakhali, Dhaka. Email: farhananila77@gmail.com
}

and which is considered essential to students' needs, which also called student housing. The hostel is built with some institutional or formal characteristics and where students have access to the university recreational facilities ${ }^{3}$. Institutional stress on the other hand occurs as a result of problems encountered in the institution's environment which could lead to condition such as, crowded time table, insufficient seats in the lecture rooms, lack of accommodation in and around the institution, problems from lecturers and incessant disruption of academic calendar ${ }^{4}$. Many universities do not have adequate accommodation facilities for their student intakes. Therefore, such students have to find private accommodation closer to their university. Hygienic facilities are essential to have a better life for human beings. However, university as a place where many people are gathered together it is difficult to maintain hygienic facilities. The majority of students in all faculties revealed that they are not satisfied with the hygienic facilities such as toilets, bathrooms and cleaning of the surrounding area ${ }^{2}$.

\section{Methodology}

This was a descriptive type of cross sectional study. The study period was from July 2017 to June 2018. The study was carried out among the students of all phases of MBBS course of 4 government and 4 non-government medical colleges of Bangladesh. Out of 8 medical colleges, 5 were within Dhaka and 3 outside of Dhaka. The sample size was 1059 students. Medical colleges were selected purposively and convenience sampling technique was adopted for student selection. The self-administered semi-structured questionnaire consisted of 87 items and all the items were measured on five points Likert scale with responses ranging

Bangladesh Journal of Medical Education 2019;10(2):23-25. C 2019 Noman et al., publisher and licensee Association for Medical Education. This is an Open Access article which permits unrestricted non-commercial use, provided the original work is properly cited. 
from "strongly disagree" to "strongly agree" except last 2 items which were open in nature and analyzed accordingly. Interpretations of the mean scores were:

- If mean score was $>4$ : Situation of the item areas was highly satisfactory

- If mean score was $>3-4$ : Situation of the item areas was satisfactory

- If mean score was $>2-3$ : Situation of the item areas was not satisfactory

- If mean score was 1-2: Situation of the item areas was very poor

The study was carried after prior consent from the students. They were free to either participate or not participate in the study. After briefly explaining the purpose and procedure of the study, the questionnaires were distributed to the students to give their opinions/views. The filled-up questionnaires were collected from the students at the end of the lecture/ tutorial/dissection class. Data were statistically analyzed by using SPSS program (IBM SPSS statistics, version 21) and represented accordingly. In-depth interview was conducted according to the teachers' convenience. The response of indepth interview was recorded by the researcher, basically in the informed paper (some respondents allowed to record).

\section{Results}

Among the 1059 respondents, 646(61\%) were female and $413(39 \%)$ were male students. Out of the 1059 respondents, $522(49 \%)$ respondents from government medical colleges and $537(51 \%)$ students from non- government medical colleges. Total 694 respondents were from medical colleges of Dhaka and 365 respondents from medical colleges of outside of Dhaka.

Table 1: Distribution of the respondents by their opinion regarding the statement related to their campus in general ( $\mathrm{n}=1059)$

\begin{tabular}{|c|c|c|c|c|c|c|}
\hline \multirow{2}{*}{$\begin{array}{l}\text { Statement related to } \\
\text { their campus }\end{array}$} & \multicolumn{5}{|c|}{ Level of agreement (corresponding score) } & \multirow[b]{2}{*}{$\operatorname{Mean} \pm$ SD } \\
\hline & SDA (1) $f(\%)$ & DDA (2) f $(\%)$ & NAND (3) $\mathrm{f}(\%)$ & A (4) $\mathrm{f}(\%)$ & SA (5) f(\%) & \\
\hline Campus is clean & $217(21)$ & $263(25)$ & $79(7.5)$ & $352(33)$ & $142(13.5)$ & $2.94 \pm 1.395$ \\
\hline Adequate clean toilet & $474(45)$ & $288(27.3)$ & $77(7.3)$ & $141(13.4)$ & $74(7)$ & $2.10 \pm 1.297$ \\
\hline Good quality canteen & $336(31.9)$ & $327(31.1)$ & $169(16)$ & $159(15.1)$ & $62(5.9)$ & $2.32 \pm 1.230$ \\
\hline Sufficient security & $283(26.9)$ & $255(24.2)$ & $117(11.1)$ & $296(28.1)$ & $101(9.6)$ & $2.69 \pm 1.375$ \\
\hline Indoor games facilities & $484(46)$ & $308(29.3)$ & $101(9.6)$ & $118(11.2)$ & $41(3.9)$ & $1.98 \pm 1.165$ \\
\hline Outdoor games facilities & $538(51.1)$ & $278(26.4)$ & $101(9.6)$ & $96(9.1)$ & $40(3.8)$ & $1.88 \pm 1.140$ \\
\hline Sufficient cultural activities & $250(23.8)$ & $263(25)$ & $169(16)$ & $290(27.6)$ & $80(7.6)$ & $2.70 \pm 1.303$ \\
\hline Good support for ill students & $229(21.7)$ & $224(21.2)$ & $216(20.5)$ & $286(27.1)$ & $100(9.5)$ & $2.81 \pm 1.304$ \\
\hline Overall mean & & & & & & $2.42 \pm 1.335$ \\
\hline
\end{tabular}

The overall mean score of 8 different issues of difficulties related to the campus was $2.42( \pm 1.335)$ revealed that the respondents were not satisfied with the campus facilities. As the distribution of the mean score of the statements about clean campus (2.94), adequate number of clean toilet (2.10), good quality canteen (2.32), sufficient security (2.69), indoor games facility (1.98), outdoor games facilities (1.88), cultural activities facilities (2.70), good support system for the ill students (2.81) were $<3$. The mean of both games facilities was $<2$ which identified the most problematic area (Table 1 ).

In this study, $42.4 \%, 43.3 \%, 44.3 \%$ of students strongly disagreed with the statement of sufficient accommodation, sufficient recreational facilities and quality foods supply in dining respectively (Table 2).

Table 2: Distribution of the respondents by their opinion regarding the statement related to the hostel in general

\begin{tabular}{|c|c|c|c|c|c|c|}
\hline \multirow{2}{*}{$\begin{array}{l}\text { Statement related to } \\
\text { the hostel }\end{array}$} & \multicolumn{5}{|c|}{ Level of agreement (corresponding score) } & \multirow[b]{2}{*}{$\operatorname{Mean} \pm$ SD } \\
\hline & SDA (1) f (\%) & DDA (2) $\mathrm{f}(\%)$ & NAND (3) $\mathrm{f}(\%)$ & $A(4) f(\%)$ & SA (5) $f(\%)$ & \\
\hline Sufficient accommodation & $435(42.4)$ & $234(22.8)$ & $88(8.6)$ & $226(22)$ & $42(4.1)$ & $2.23 \pm 1.30$ \\
\hline Clean & $409(39.8)$ & $243(23.7)$ & $109(10.6)$ & $224(21.8)$ & $42(4.1)$ & $2.27 \pm 1.29$ \\
\hline Secured & $370(\underline{36})$ & 203(19.7) & $153(15)$ & $245(23.8)$ & $57(5.5)$ & $2.43 \pm 1.33$ \\
\hline Favorable for the learning & 291(28.4) & $219(21.3)$ & $185(18)$ & $275(26.8)$ & $56(5.5)$ & $2.60 \pm 1.29$ \\
\hline Quality dining foods & $453(\underline{44.3})$ & $237(23.2)$ & 151(14.8) & $139(13.6)$ & $42(4.1)$ & $2.10 \pm 1.22$ \\
\hline Sufficient recreation facilities* & $444(\underline{43.3})$ & $258(25.2)$ & $147(14.3)$ & $137(13.4)$ & $39(3.8)$ & $2.09 \pm 1.20$ \\
\hline Regular supervised by the authority & $390(38.1)$ & $200(19.5)$ & $161(15.7)$ & $225(22)$ & $48(4.7)$ & $2.36 \pm 1.303$ \\
\hline Overall mean & & & & & & $2.29 \pm 1.292$ \\
\hline
\end{tabular}

*TV, internet, common room, indoor games

Bangladesh Journal of Medical Education 2019;10(2):23-25 


\section{Discussion}

In this study, it was revealed that students faced more difficulties in outdoor games facilities $(51.1 \%)$ than indoor games $(46 \%)$. They also faced problem with adequate number of clean toilet $(45 \%)$, cleanliness of campus (20.6\%) and support system (21.7\%). These findings are consistent with another study, where revealed $61.2 \%$ students reported that the indoor/outdoor games facilities limited in the institution $^{5}$. But in the question of sufficient security, the result is not consistent. In this study $51.1 \%$ students mentioned about the insufficient security whereas $62.2 \%$ students agreed that they were secured in the campus ${ }^{5}$. There was easy entry of outsiders in the campus. Probably this is the cause of the inconsistence of this finding.

Hostel accommodation facilities are the basic requirement for the medical students. The total mean score of six issues related with the hostel was 2.29(1.29). It was identified that students encountered more problems for insufficient accommodation, dining, insufficient recreational facilities like TV, internet, common room, indoor games), irregular supervision (38.1\%), uncleanliness (39.8\%) and insecurity $(36 \%)$ in the hostel. Similar results was found in another study of Hassan (2017), where revealed 59.6\% students reported that accommodation was not sufficient and uncomfortable in Bangladesh. Similar study was also found in Sri-Lanka where reported insufficient accommodation ${ }^{2}$. From the open part of the questionnaire, it was found that the hostel accommodation was costly and insufficient in nongovernment medical colleges. On the other hand, cleanliness and security problem were more in government medical colleges. Food quality of the dining were not satisfactory in all sectors. There were differences in the perceived stress among the students residing in the hostel. Stress was found to be double in hostel students in comparison to that in the students of the local area ${ }^{6}(\mathrm{p}<0.05)$. The overall mean score of the six statements in relation to the classroom facilities was 3.28(1.191). The result about the classroom statements were satisfactory to the students.

\section{Conclusion}

This paper attempted to identify the undergraduate medical students' problems in relation to the institution and hostel campus on the. In this study, students highlighted the institutional related difficulties particularly unclean campus, inadequate number of clean toilet within the institution, insufficient games (both indoor and outdoor) facilities, good quality canteen, insufficient hostel accommodation and lowquality dining food. Due to the lack of the supervision of the authority and easy entry of the outsiders, cleanliness of the campus could not be maintained. There was no time schedule for the indoor games in daily class routine and lack of proper field for outdoor games in case of non-government medical colleges of Bangladesh. To generalized the study findings, further large scale quantitative research along with focus group discussion is recommended which may assist the higher authority to take deliberate steps to overcome the difficulties of the undergraduate medical students of Bangladesh.

\section{Recommendation}

Based on the study findings, following recommendations have been formulated according to the students ranked difficulties:

- The concerned authority should ensure enough buckets and bins around the campus and at the same time should apply some strict rules and regulation for maintenance of the clean campus. The authority should ensure sufficient number of clean toilet with hand washing facilities in every department of the institution.

- College canteen should be maintained the quality in food processing and serving. Outsiders should be prohibited in canteen and campus without pass to ensure security.

- There should be adequate outdoor games facilities in every medical colleges to reduce their stress in examination loaded medical life.

- Hostel accommodation and recreation facilities should be increased and maintained accordingly.

\section{References}

1. Sherina M S, Rampal L, Kaneson N. Psychological Stress among Undergraduate Medical Students. MedJ Malaysia 2004; 59 (2): June 2004.

2. Perera R M. A. N. Problems faced by undergraduates in the learning environment: some evidences from a Sri Lanka University. Sri Lanka journal of Advanced social studies 2013;3(1):77-100.

3. Khozaei F, Ayub N, Hassan AS \& khozaei Z .The Factors Predicting Students' Satisfaction with University Hostels, Case Study, University Sains Malaysia; www.ccsenet.org/ach Asian Culture and History Vol. 2, No. 2; July 2010. Article · June 2010 DOI: $10.5539 /$ ach.v2n2p148 Source: DOAJ

4. Adesola AF \& Arowolo DO. Physiological, Emotional and Institutional Stress as Correlate of Behavioural Problem Among University Undergraduate in South West Nigeria; European Journal of Research and Reflection in Educational Sciences 2014, 2 (4) : 58-61, ISSN 2056-5852

5. Hassan Z. Activities reducing the stress among undergraduate medical students of selected medical colleges of Bangladesh: Teachers and Students perception. MMEd Thesis; Centre for medical education, Bangladesh; 2017. Retrived on 20.01.18 from CME library.

6. Shah C, Trivedi RS, Diwan J, Dixit R, Anand A K. Common Stressors and Coping of Stress by Medical Students. Journal of Clinical and Diagnostic Research [Serial Online] 2009 August [Cited: 2009 August 7]; 3:1621-1626 